\section{Models to Describe Cycas micronesica Leaf and Strobili Development}

\author{
Thomas E. Marler ${ }^{1}$ and Nirmala Dongol \\ Western Pacific Tropical Research Center, College of Natural and Applied \\ Sciences, University of Guam, UOG Station, Mangilao, Guam 96923
}

Additional index words. Cycadaceae, Cycas micronesica, ontogeny, organ development, phenology

\begin{abstract}
Cycas micronesica leaf and strobili expansion patterns were measured in three locations and seasons on Guam and then were fitted with non-linear models to evaluate the use of the parameters for informing management decisions. All growth curves except for microstrobili height conformed to a negative exponential function. Microstrobili height development could not be fitted with any traditional linear or non-linear function, so spline models were used to smooth the effect of elapsed days. Leaf and leaflet expansion patterns were influenced by habitat and season, indicating development of the vegetative organ is plastic. In contrast, the models that described development of megasporophyll length, microstrobili height, and microstrobili diameter were not influenced by habitat or season. Moreover, seed diameter developmental patterns were only minimally influenced by location. These results indicate developmental patterns of the reproductive structures were primarily constitutive. We have demonstrated two empirical approaches to fitting models of Cycas micronesica organ growth and development and that both methods are useful for determining the influence of spatial or temporal factors in the timing of organ development. This approach may be used to inform horticultural or conservation questions of other rare cycad species.
\end{abstract}

Understanding the developmental patterns and factors that control expansion of vegetative and reproductive organs is of fundamental importance for refining conservation protocols for rare plants. For example, the period of vulnerability to arthropod herbivory is ephemeral for many plant organs, and prophylactic protection activities can be restricted to the vulnerable phase. This requires a workable understanding of the temporal dynamics of that phase. In addition, understanding the pattern and timing of pollen display and dispersal within male reproductive organs versus that of ovule display and receptivity on female reproductive organs is needed for management of dioecious species to ensure successful propagation operations. The vast majority of research in the literature that describes growth and development of Spermatophyte organs has been directed toward fleshy fruits (e.g., Coombe, 1976), because these organs are of special interest to horticulturists (Leopold and Kriedemann, 1975).

The three families that comprise contemporary cycad species are of interest for various reasons, including striking morphological features and historical importance in vascular plant diversification (Norstog and Nicholls, 1997). Because more than $60 \%$ of described cycad species are threatened and some critically endangered (IUCN, 2010), concern for

Received for publication 6 Apr. 2011. Accepted for publication 25 June 2011.

Support provided by USDA CSREES \#2003-05495. We thank George Fernandez, UNR Center for Research Design and Analysis, for statistical analyses. ${ }^{1}$ To whom reprint requests should be addressed; e-mail tmarler@uguam.uog.edu. active conservation efforts in horticultural settings has increased. Despite this interest, empirical studies on issues that directly inform management decisions have been few (but see Calonje et al. 2010). This deficiency is not restricted to Cycadales, because most active management programs for threatened and endangered plant species are based on general field observations and not on experimental studies (Given, 1994).

Field studies that tabulated frequency of reproductive events have been reported for numerous cycad species (Clark and Clark, 1987, 1988; Keppel, 2001; Negron-Ortiz and Gorchov, 2000; Ornduff, 1987, 1991, 1996; Tang, 1990; Terry et al., 2008; Vovides, 1990). Expansion of male cones during the few days that define the pollination stage has been described for Dioon edule (Tang, 1987), Encephalartos hildebrandtii (Tang, 1989), and Zamia pumila (Tang, 1990). Some histological studies of organ development have been reported for a range of species (Stevenson, 1988. and citations therein; Vovides et al., 1993). Moreover, the influence of organ age on physiological traits has been reported for one Cycas species (Marler, 2007; Marler et al., 2006). However, to our knowledge, no reports have mathematically characterized organ expansion patterns to establish a foundation for understanding levels of plasticity and improving accuracy in management decisions.

Our foremost objective was to quantify expansion rates of various components of leaves and strobili for the endangered Cycas micronesica and then determine if the growth patterns were amenable to being fitted with mathematical models. We then used the appropriate models to demonstrate if this approach can be exploited to determine if these developmental processes are constitutive or if temporal and spatial factors significantly influence organ development traits.

\section{Materials and Methods}

Emerging $C$. micronesica leaves were selected in February and May 2004 from three plants in each of three locations on the island of Guam. Three leaves on each plant were tagged for a total of nine measurements per location on each date. The locations were separated by $20 \mathrm{~km}$ and included an east coast location where abiotic stresses are most extreme, a west coast location where plants are protected from the desiccating effects of chronic trade winds and aerosol oceanic salt spray, and a location in central Guam. The differences in these combined stressors between the east and west coast is enough to elicit a significant difference in reproductive effort (Marler and Niklas, 2011). The lengths of each rachis and petiole were measured every 3 to $4 \mathrm{~d}$ during the phase of rapid expansion and weekly thereafter. Additionally, leaflet length in the median position of each rachis was measured.

Emerging microstrobili were selected on three plants in each location in Feb., May, and Nov. 2004. Microstrobili height was measured directly and strobili circumference was measured with a flexible tape to ensure minor deviations from radial symmetry did not confound sequential measurements. Measurements were made at 3- to 4-d intervals during the phases of rapid expansion and weekly at other times. Strobilus diameter was calculated from the circumference measurements.

The female Cycas strobilus is comprised of a loose assemblage of individual megasporophylls. Plants with emerging megasporophylls were selected within each of the locations in Feb. 2004. The duration of growth of megastrobili is extensive, so we did not repeat the selection of additional replications in subsequent seasons. Four plants in the east coast and central locations were selected, and five plants in the west coast habitat were selected. Three sporophylls on each plant were tagged. Sporophyll length and seed diameter were measured every 3 to $4 \mathrm{~d}$ during rapid expansion phases and every 10 to $14 \mathrm{~d}$ thereafter. Seeds of this species do not exhibit radial symmetry but are isobilateral. Therefore, we positioned the seed diameter measurements to quantify the widest orientation at the midpoint of the seed.

The mean of the three tagged leaves, leaflets, microstrobili, megasporophylls, or seeds from each plant was used to represent each of these replications in the statistical analyses. Preliminary graphical analysis of each organ expansion data set revealed that the expected relationship between leaf, leaflet, or megasporophyll length expressed as a function of elapsed days was the negative exponential function $\mathrm{Y}=\mathrm{a}-\mathrm{b}^{*} \mathrm{e}^{(-\mathrm{kx})}$. Similarly, the relationship between male strobili and seed diameter as a function of elapsed days followed the same model. After fitting several starting values in the SAS NLIN procedure (SAS Institute, Inc., Cary, NC), the final negative 
exponential growth model was fitted for each habitat, season, and replication combination. The three negative exponential growth model parameters, $a, b$, and $k$ were calculated for each replication and used to create a SAS data set. Then a GLM model was fitted to determine the significance of three habitats and two (leaf and megastrobili components) or three (microstrobili) seasons on $a, b$, or $k$.

Microstrobili height growth pattern was not consistent with common linear or nonlinear functions. Therefore, spline models were tried to model the non-linear growth patterns. We used the generalized mixed model with spline fit using the RSmooth option in the Random statement in SAS GLIMMIX, which uses a semiparametric approach to smooth curves (Rupper et al., 2003). This analysis tested the main sources of variation as season, habitat, and elapsed days with the effect of elapsed days fitted as a spline effect.

\section{Results}

Leaves. Leaf length was comprised exclusively of rachis for the first 8 to $10 \mathrm{~d}$ after emergence (Fig. 1A), after which the apical portion of the petiole emerged and continued leaf extension included both petiole and rachis (Fig. 1B). Petiole length reached a maximum by 18 to $20 \mathrm{~d}$, and rachis length reached a maximum by $30 \mathrm{~d}$ (Fig. 2A). Total leaf length increased slowly for the first 7 to $10 \mathrm{~d}$ after emergence from the stem apex; then a linear growth phase with expansion rates of 8 to $11 \mathrm{~cm} \cdot \mathrm{d}^{-1}$ was sustained until $\approx 30 \mathrm{~d}$ after emergence.

Leaves emerged from the stem apex with circinate leaflets (Fig. 1C), and leaflets remained so until $\approx 20 \mathrm{~d}$ after emergence. Thereafter, leaflets unfolded and exhibited rapid extension with increases of $\approx 1.5 \mathrm{~mm} \cdot \mathrm{d}^{-1}$ being maintained for 14 to $15 \mathrm{~d}$ (Fig. 2B).

After this 35-d expansion phase, the leaves ranged in length from 101 to $185 \mathrm{~cm}$ and leaflets range in length from 169 to $275 \mathrm{~mm}$. Percentage of total leaf length represented by petiole length ranged from $21 \%$ to $35 \%$. Leaflet color continued to change as the leaves aged (Fig. 1D), until the new leaves portrayed a general appearance that was homogeneous with subtending leaves by Days 80 to 90 .

The main effect of season was significant for $a, b$, and $k$ non-linear model parameters that described total leaf length and the main effect of location was significant for $k$ only (Table 1). Based on this outcome, six separate negative exponential growth models were fitted for three location and two season combinations (Table 2). Season and location did not influence the non-linear model parameter $a$ for the function that described total leaflet length (Table 1). However, the main effects of season, location, and their interaction influenced $b$ and $k$ non-linear parameters for leaflet expansion. Therefore, six separate negative exponential growth models were fitted for three location and two season combinations (Table 2).

Female sporophylls and seeds. Megasporophylls emerged from the stem apex in a
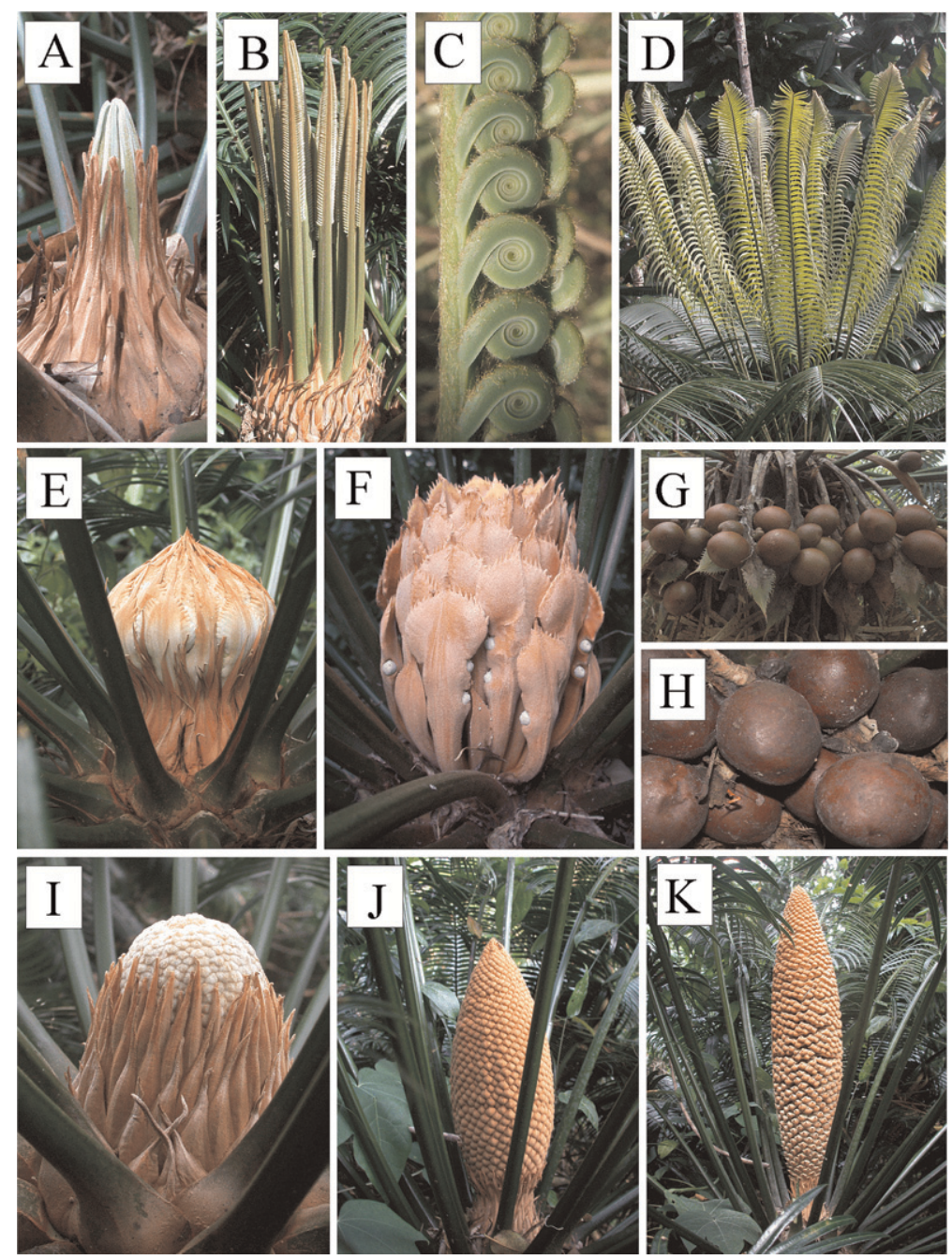

Fig. 1. Phenotype of Cycas micronesica organ expansion stages. (A) Newly emerging flush of leaves. (B) Erect leaves depict initial stages of expansion. (C) Cycas leaves express circinate leaflets initially. (D) Leaf color of young leaves is dissimilar to that of mature leaves until $\approx 3$ months. (E) Newly emerging megastrobili at Day 13. (F) Appearance of megastrobili at Day 35. (G) Bronze seed appearance at maximum diameter, Day 420. (H) Dark brown seed appearance after shrinkage of seed integument tissue, Day 590. (I) Newly emerging microstrobilus at Day 2. (J) Microstrobilus at Day 54 before final stage of rapid height extension. (K) Microstrobilus at pollen dispersal and full height extension, Day 67.

linear growth phase with extension rates of $8 \mathrm{~mm} \cdot \mathrm{d}^{-1}$ (Fig. 3A). Mature length was achieved in $\approx 30 \mathrm{~d}$ when sporophylls were still erect and ranged from 22.8 to $23.6 \mathrm{~cm}$. Sporophyll length did not change thereafter, but orientation changed as sporophylls began to radiate away from vertical. This change in orientation continued until sporophylls were positively gravitropic. Diagnosis of the pollination stage by olfactory perception of the characteristic aromatic volatiles occurred at $28.7 \pm 0.5 \mathrm{~d}$ after megasporophyll emergence from the stem apex.

Ovules emerged on the sporophylls $\approx 11$ $\mathrm{mm}$ in diameter (Fig. 3B). Diameter did not change while sporophyll extension was ongoing, but a linear increase in seed diameter of 0.4 to $0.5 \mathrm{~mm} \cdot \mathrm{d}^{-1}$ was initiated thereafter in response to pollination events. The linear phase was retained until $\approx 130 \mathrm{~d}$ after sporophyll emergence. Thereafter, seed diameter continued to increase at a progressively slower pace until Day 300 when diameter ranged from 59 to $69 \mathrm{~mm}$. Finally, beginning Day 550 , the seed diameter decreased slightly as seed integument tissue lost hydration, and diameter at Day 690 was 56 to $66 \mathrm{~mm}$.

The GLM model determined that location did not influence sporophyll development. Therefore, sporophyll extension from all three locations was described by one nonlinear model, Length $=23.3731-16.8980^{*}$ $\mathrm{e}^{(-0.06793 * \text { days })}$. The main effect of location also did not influence the non-linear model parameter $a$, but it did influence model parameters $b(P \leq 0.0088)$ and $k(P \leq 0.0300)$ for seed diameter developmental patterns. Based on this outcome, three separate negative exponential growth models were fitted for the three locations (Table 3 ). The differences were minimal in comparison with differences in leaf and leaflet development. The influence of differences in $k$ (Table 3 ) was evident in a more gradual inflection of the growth curve for the east coast location in comparison with the other two locations. 

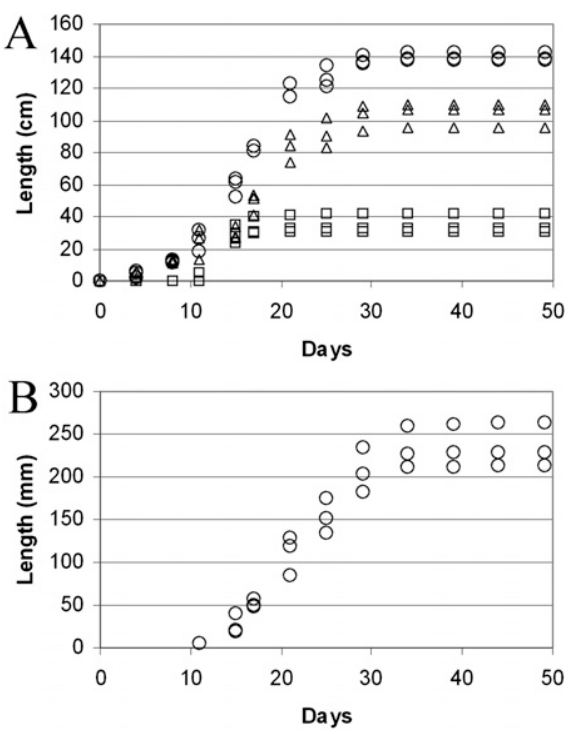

Fig. 2. (A) Length of Cycas micronesica petiole $(\square)$, rachis $(\triangle)$, and total leaf $(\bigcirc)$ as a function of days after emergence. At least one of the three non-linear model parameters was significant for location and season effects. Therefore, data are exclusively from a west coast location on Guam beginning Feb. 2004. (B) Length of leaflets from the same leaves.

Table 1. Significance of two seasons and three locations on the parameters $a, b$, and $k$ that describe the negative exponential function $\mathrm{Y}=$ $\mathrm{a}-\mathrm{b}^{*} \mathrm{e}^{(-\mathrm{kx})}$ for total Cycas micronesica leaf $(\mathrm{cm})$ and leaflet $(\mathrm{mm})$ extension with elapsed days as $\mathrm{x}$-axis.

\begin{tabular}{lccc}
\hline Source of variation & $a$ & $b$ & $k$ \\
\hline Location & Leaf & & \\
Season & 0.1435 & 0.1498 & 0.0452 \\
Location $\times$ season & 0.0374 & 0.0387 & 0.0049 \\
& 0.5441 & 0.5546 & 0.8571 \\
& & & \\
Location & Leaflet & & \\
Season & 0.1531 & 0.0015 & $<0.0001$ \\
Location $\times$ season & 0.1179 & 0.0065 & 0.0011 \\
& 0.2977 & 0.0018 & 0.0012 \\
\hline
\end{tabular}

Table 2. Model parameters for the negative exponential function $\mathrm{Y}=\mathrm{a}-\mathrm{b}^{*} \mathrm{e}^{(-\mathrm{kx})}$ for total Cycas micronesica leaf $(\mathrm{cm})$ and leaflet $(\mathrm{mm})$ extension fitted for six locations and seasons.

\begin{tabular}{lcrcc}
\hline Location & Season & $a$ & $b$ & $k$ \\
\hline East coast & Feb. & 214.241 & 228.772 & -0.03039 \\
East coast & May & 307.002 & 323.412 & -0.01825 \\
Central & Feb. & 156.184 & 174.063 & -0.04581 \\
Central & May & 208.248 & 227.242 & -0.02934 \\
West & Feb. & 211.909 & 231.350 & -0.03414 \\
$\quad$ coast & & & & \\
$\begin{array}{c}\text { West } \\
\quad \text { coast }\end{array}$ & May & 388.458 & 409.925 & -0.02254 \\
& & & &
\end{tabular}

\begin{tabular}{lllrl} 
East coast & Feb. & 215.917 & 262.491 & -0.06699 \\
East coast & May & 315.465 & 498.204 & -0.06741 \\
Central & Feb. & 221.230 & 22004.3 & -0.30072 \\
Central & May & 297.659 & 1215.61 & -0.09064 \\
$\begin{array}{c}\text { West } \\
\quad \text { coast }\end{array}$ & Feb. & 303.005 & 1274.25 & -0.07264 \\
$\begin{array}{c}\text { West } \\
\quad \text { coast }\end{array}$ & May & 961.168 & 1345.42 & -0.04221 \\
\hline
\end{tabular}

Male strobili. Microstrobili emerged with a rapid linear height growth phase that lasted 20 to $25 \mathrm{~d}$ (Fig. 4A). Strobili continued to increase in height at a continually slowing rate for another $30 \mathrm{~d}$. At the end of this stage, the expansion rate was minimal. Then within 7 to $9 \mathrm{~d}$, these microstrobili doubled in height. This final rapid phase of extension was not evenly distributed vertically. Initially the central axis expanded at the base to loosen the basal microsporophylls, and the loosening progressed in an acropetal manner until all microsporophylls were loosened. Ultimate mature height was achieved in $60.4 \pm 0.8 \mathrm{~d}$ and ranged from 35.3 to $56.5 \mathrm{~cm}$. Microsporangia opened in a pattern that mirrored that of sporophyll loosening with basal microsporangia dispersing pollen initially at $62.4 \pm 1.0 \mathrm{~d}$ and apical microsporangia exhibiting the final pollen dispersal at $67.8 \pm 0.7 \mathrm{~d}$.

Increase in microstrobili diameter did not follow the two-phase pattern that characterized increase in height. Instead, a smooth pattern occurred with a linear phase initially followed by a decrease in diameter increment (Fig. 4B). After pollen dispersal, these microstrobili declined in diameter as microsporophyl tissues began to become dehydrated. Maximum diameter ranged from 10.3 to $14.5 \mathrm{~cm}$ and occurred at 54 to $71 \mathrm{~d}$ after emergence. Microstrobili diameter decreased 5\% to $18 \%$ during the 2 weeks after pollen shed.

Table 3. Model parameters for the negative exponential function $\mathrm{Y}=\mathrm{a}-\mathrm{b} \mathrm{e}^{(-\mathrm{kx})}$ for Cycas micronesica seed diameter $(\mathrm{mm})$ expansion fitted for three locations.

\begin{tabular}{lccc}
\hline Location & $a$ & $b$ & $k$ \\
\hline East coast & 61.5874 & 82.0228 & -0.01342 \\
Central & 62.1592 & 85.1844 & -0.01176 \\
West coast & 61.7251 & 73.8347 & -0.00975 \\
\hline
\end{tabular}

The GLM model determined that location did not influence microstrobili diameter development. Therefore, microstrobili diameter from three locations and three seasons could be described by one non-linear model:

$$
\begin{aligned}
& \text { Diameter } \\
& \quad=116.8054-115.1004 * \mathrm{e}^{\left(-0.088926^{*} \text { days }\right)} .
\end{aligned}
$$

Male strobili height exhibited the most complex growth pattern observed in this study. Because of the non-parametric spline model fit, no model parameter estimates are available. However, the GLIMMIX procedure allowed the test of significance for the main effect of location and season along with the spline effect of elapsed days, so our objective of defining the influence of location and season on the organ growth pattern was met. The Type III tests of location and season main effects did not influence the changes in male strobili height, but elapsed days was significant $(P \leq$ 0.0002).

\section{Discussion}

We have demonstrated the use of two statistical approaches to describe cycad organ development and have shown that both approaches are amenable to quantifying the influence of temporal and spatial factors on the processes. Whenever the data could be fitted with a conventional non-linear model, we generated model parameters for each replication and then subjected each parameter to traditional analysis of variance with season and location as sources of variation. When the growth curves were atypical, we used elapsed days, season, and location as main sources of variation with elapsed days tested as a spline effect. Both approaches enabled us to uncover the level of plasticity of Cycas micronesica
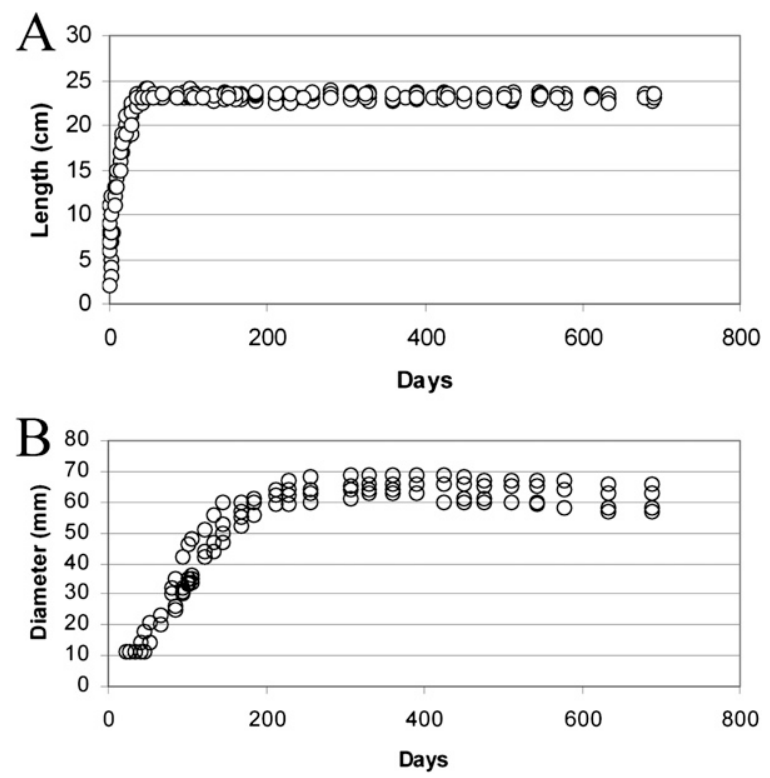

Fig. 3. (A) Length of Cycas micronesica megasporophyll as a function of days after emergence. No parameter from non-linear models was significant, so data are from all locations. (B) Seed diameter as a function of days after emergence. The effect of location was significant for two of the three non-linear model parameters, so data are exclusively from a central Guam habitat. 

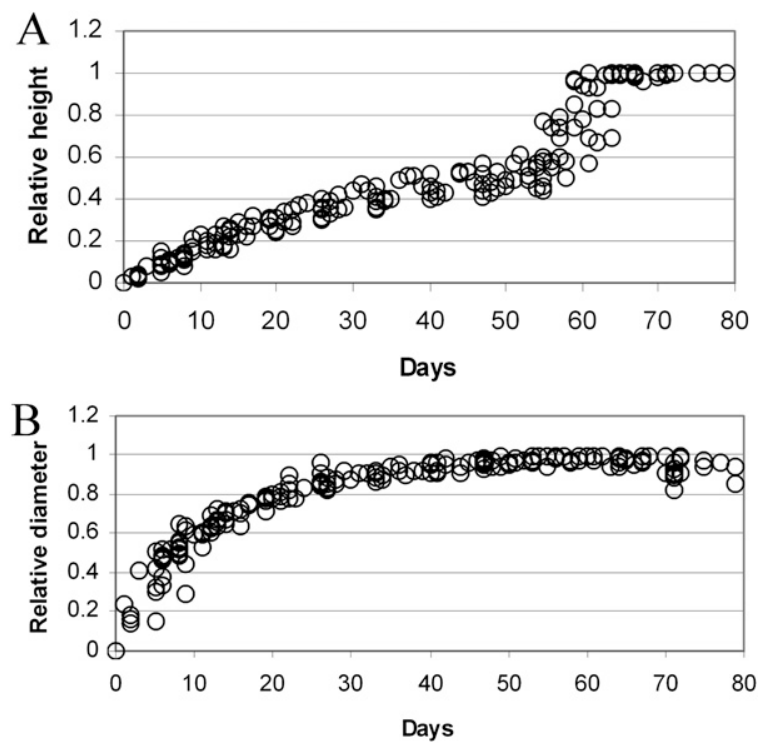

Fig. 4. (A) Height of Cycas micronesica microstrobili as a function of days after emergence. Location and season did not influence the development of microstrobili height; therefore, data are from all locations and seasons. Data are standardized for each replication as quotient of ultimate absolute height, which ranged from 35.3 to $56.5 \mathrm{~cm}$. (B) Microstrobili diameter as a function of days. The three non-linear model parameters were not influenced by location or season; therefore, data are from all locations and seasons. Data are standardized for each replication as a quotient of ultimate absolute diameter, which ranged from 11.1 to $14.5 \mathrm{~cm}$.

leaf and strobili development among seasons and locations.

The shape and timing of $C$. micronesica reproductive organ expansion were relatively independent of location and season. In contrast, leaf and leaflet expansion were influenced by these spatial and temporal factors. Thus, our results conform to the general principles of the Berg hypothesis (Berg, 1959, 1960), which argues that phenotypic variation in reproductive structures is decoupled from that of vegetative organs as a result of selection generated by pollinators.

Horticulturists may exploit this approach in studying organ expansion dynamics for various applications. For example, this knowledge may inform experimental design for understanding the factors that regulate leaf expansion (Dale, 1988) and timing of the processes related to the transition from heterotrophic tissue to autotrophic tissue (Turgeon, 1989). Cycad organ ontogeny is a relatively unexplored field, and studies are needed to determine when cell division versus cell expansion processes occur within seed integument, embryo, and gametophyte tissues for female plants or during the highly contrasting first and second height expansion phases of the microstrobili development for male plants.

A thorough understanding of cycad leaf development is also of critical importance for horticulturists. For example, the Cycas-specific Chilades pandava Horsfield butterfly ovipositions on expanding tissue exclusively. Larvae access to a newly emerging leaf leads to consumption of the entire structure, including petiole and rachis. In contrast, if ovipositions are delayed until the rachis is partially expanded, then larval damage is restricted to a portion of the leaflets. Therefore, timing of prophylactic treatments within just a few days dictates whether a portion or all of the leaf are consumed by this lepidopteran pest.

Knowledge of the timing of reproductive organ development is additionally crucial for successful sexual propagation of rare cycad species that are represented by only a few individuals. All cycads are dioecious, so a grower that does not have access to cryostorage facilities must enable synchrony of reproductive phenology among individuals to realize success (Marler, 2010). This can best be done with a detailed understanding of the timing of development and the factors that affect plasticity of organ development in relation to female ovule receptivity and male pollen dissemination. The recent advent of efficient international communications among cycad enthusiasts has enabled extensive coordination of pollen provision among growers despite their separation by great geographic distances. A better understanding of strobili development and the factors that affect the timing of that development will greatly increase the success rates for growers working collaboratively to propagate rare cycad species.

Our results reveal great disparity in the window of time between reproductive organ emergence and pollination with male strobili requiring 33 to $40 \mathrm{~d}$ more than female strobili to reach the pollination phase. The most accurate method for projecting the appropriate date for pollination stage would depend on recording the emergence date of strobili. Megastrobili receptivity can be expected at Day 28, and the initiation of a 5- to 6-d window of pollen shed can be expected for microstrobili at Day 62. If the emergence date is missed, our results illuminate two other methods for accurate estimation. Megasporophyll extension rates of $8 \mathrm{~mm} \cdot \mathrm{d}^{-1}$ occurred for the first few days; therefore, length of developing sporophylls could be measured and then Day 0 could be retrospectively estimated using this stable extension rate. The female aromatic stage at Day 28 could then be projected with accuracy because of the limited variability of ultimate megasporophyll length. In contrast, microstrobili height was highly heterogeneous, so use of the growth rate within the initial linear phase to retrospectively estimate Day 0 would be less accurate. However, the appearance of the microstrobili just before initiation of the final doubling of height (Fig. $1 \mathrm{~J})$ is distinguishable with full size and mature appearance of the surface of each microsporophyll. At this stage, the sporophylls appear to adhere in a manner similar to the carpels that comprise the syncarp of pineapple [Ananas comosus (L.) Merr.]. Daily inspection of the microstrobili base at this stage until loosening of sporophylls begins can be used to accurately estimate $\approx 7 \mathrm{~d}$ until initiation of pollen dehiscence.

Season and habitat interactively influenced leaf development. The primary abiotic factors influenced by season on Guam are rainfall and photoperiod. The major rainy season is July to December, and the major dry season is January to June. Thus, soil moisture reserves during the February flush were less limiting than during the May flush. Heterogeneity of photoperiod or soil moisture reserves may have accounted for the significant seasonal differences. The locations vary in direct abiotic stressors with the east coast location receiving desiccating trade winds and chronic aerosol deposits of oceanic mist. These localized characteristics may have accounted for the significant location differences.

We have shown the use of this approach for comparing season and location diversity in relation to the timing of organ development of a single species. Temporal comparisons with this approach could be extended to annual cycles, and spatial comparisons could be extended to multiple islands or countries for species with wide ranges. Taxonomic comparisons could be extended to congenerics rather than disjunct locations of a single species. Finally, we propose that this approach could be used to understand any changes in organ development that result from disturbances. This may include the patterns of shortterm recovery from abiotic disturbances such as tropical cyclones (Marler and Hirsh, 1998) or fire (Keppel, 2001; Negron-Ortiz and Gorchov, 2000). Furthermore, it may include the influence of biotic disturbances such as invasions of exotic herbivores (Marler and Muniappan, 2006) or various forms of human disturbance (Pérez-Farrera et al., 2006).

As a group, cycads are important as a result of unique traits such as their basal position in seed plant phylogenetic relations (Norstog and Nicholls, 1997). However, research on organ development of cycads has been ignored in relation to other horticultural species that historically have commanded greater economic value on the national or international market. The three families, 10 
genera, and $300+$ species offer much in providing answers to horticultural questions of importance to biologists, conservationists, and ecologists. Although the concepts that underlie our objectives are ecumenical among biologists, we are the first to use this empirical approach to describe cycad organ development. We intend for this report to evoke new ideas for improving cycad conservation efforts. Toward that end, we hope that our approach may serve as an archetype for an informative mechanism to study cycad growth and development.

\section{Literature Cited}

Berg, R.L. 1959. A general evolutionary principle underlying the origin of developmental homeostasis. Amer. Nat. 93:103-105.

Berg, R.L. 1960. The ecological significance of correlation pleiades. Evolution 17:171-180.

Calonje, C., C. Husby, and M. Calonje. 2010. Germination and early seedling growth of rare Zamia spp. in organic and inorganic substrates: Advancing ex situ conservation horticulture. HortScience 45:679-683.

Clark, D.A. and D.B. Clark. 1987. Temporal and environmental patterns of reproduction in $\mathrm{Za}$ mia skinneri, a tropical rain forest cycad. J. Ecol. 75:135-149.

Clark, D.B. and D.A. Clark. 1988. Leaf production and the cost of reproduction in the neotropical rain forest cycad, Zamia skinneri. J. Ecol. 76: $1153-1163$.

Coombe, B.G. 1976. The development of fleshy fruits. Annu. Rev. Plant Physiol. 27:207-228.

Dale, J.E. 1988. The control of leaf expansion. Annu. Rev. Plant Physiol. Plant Mol. Biol. 39:267-295.

Given, D.R. 1994. Principles and practice of plant conservation. Timber Press, Portland, OR.

IUCN. 2010. The IUCN Red List of Threatened Species October 2010 update: Cycad Facts. 9
Aug. 2011.<http://cmsdata.iucn.org/downloads/ cycad_factsheet_final.pdf $>$.

Keppel, G. 2001. Notes on the natural history of Cycas seemannii (Cycadaceae). South Pacific J. Natural Sci. 19:35-41.

Leopold, A.C. and P.E. Kriedemann. 1975. Plant growth and development. 2nd Ed. McGraw-Hill, New York, NY.

Marler, T.E. 2007. Age influences photosynthetic capacity of Cycas micronesica leaves. Mem. N. Y. Bot. Gard. 97:193-203.

Marler, T.E. 2010. Time-size trade-offs in responses of cycads to male cone herbivory. Communicative and Integrative Biology 3 : 602-603.

Marler, T.E. and H. Hirsh. 1998. Guam's Cycas micronesica population ravaged by Supertyphoon Paka. HortScience 33:1116-1118.

Marler, T.E., V. Lee, J. Chung, and C.A. Shaw. 2006. Steryl glucoside concentration declines with Cycas micronesica seed age. Funct. Plant Biol. 33:1-6.

Marler, T.E. and R. Muniappan. 2006. Pests of Cycas micronesica leaf, stem, and male reproductive tissues with notes on current threat status. Micronesica 39:1-9.

Marler, T.E. and K. Niklas. 2011. Reproductive effort and success of Cycas micronesica K.D. Hill are affected by habitat. Intl. J. Plant Sci. 172:700-706.

Negron-Ortiz, V. and D.L. Gorchov. 2000. Effects of fire season and postfire herbivory on the cycad Zamia pumila (Zamiaceae) in slash pine savanna, Everglades National Park, Florida. Intl. J. Plant Sci. 161:659-669.

Norstog, K.J. and T.J. Nicholls. 1997. The biology of the cycads. Cornell University Press, Ithaca, New York.

Ornduff, R. 1987. Sex ratios and coning frequency of the cycad Zamia pumila L. (Zamiaceae) in the Dominican Republic. Biotropica 19:361-364.

Ornduff, R. 1991. Coning phenology of the cycad Macrozamia riedlei (Zamiaceae) over a fiveyear interval. Bull. Torrey Bot. Club 118:6-11.
Ornduff, R. 1996. Gender performance in a cultivated cohort of the cycad Zamia integrifolia (Zamiaceae). Amer. J. Bot. 83:1006-1015.

Pérez-Farrera, M.A., A.P. Vovides, P. Octavio-Aguilar, J. González-Astorga, J. de la Cruz-Rodríguez, R. Hernández-Jonapá, and S. Maza VillalobosMéndez. 2006. Demography of the cycad Ceratozamia mirandae (Zamiaceae) under disturbed and undisturbed conditions in a biosphere reserve of Mexico. Plant Ecol. 187:97-108.

Rupper, D., M.P. Wand, and R.J. Carroll. 2003. Semiparametric regression. Cambridge University Press, Cambridge, UK.

Stevenson, D.W. 1988. Stobilar ontogeny in the Cycadales, p. 205-224. In: Liens, P., S.C. Tucker, and P.K. Endress (eds.). Aspects of floral development. J. Cramer, Berlin, Germany.

Tang, W. 1987. Heat production in cycad cones Bot. Gaz. 148:165-174.

Tang, W. 1989. Male cycad cone structure and function. Encephalartos 20:25-28.

Tang, W. 1990. Reproduction in the cycad Zamia pumila in a fire-climax habitat: An eight-year study. Bull. Torrey Bot. Club 117:368-374.

Terry, I., P.I. Forster, C.J. Moore, R.B. Roemer, and P.J. Machin. 2008. Demographics, pollination syndrome and conservation status of Macrozamia platyrhachis (Zamiaceae), a geographically restricted Queensland cycad. Aust J. Bot. 56:321-332.

Turgeon, R. 1989. The sink-source transition in leaves. Annu. Rev. Plant Physiol. Plant Mol. Biol. 40:119-138

Vovides, A.P. 1990. Spatial distribution, survival, and fecundity of Dioon edule (Zamiaceae) in a tropical deciduous forest in Veracruz, Mexico, with notes on its habitat. Amer. J. Bot. 77:15321543 .

Vovides, A.P., K.J. Norstog, P.K.S. Fawcett, M.W Duncan, R.J. Nash, and D.V. Molsen. 1993 Histological changes during maturation in male and female cones of the cycad Zamia furfuracea and their significance in relation to pollination biology. Bot. J. Linn. Soc. 111:241-252. 